\title{
https://doi.org/10.30853/filnauki.2020.5.23
}

\section{Ван Лина}

Особенности реакций-реплик с вопросительным словом "почему"

В статье представлена попытка описания особенностей реакций-реплик с вопросительным словом "почему", которые широко распространены в русской диалогической речи. Цель исследования - подробно проанализировать на основе материалов НКРЯ особенности структуры, смысла, прагматической функции и интонации "почему"реплик как реакций на модус. Научная новизна заключается в том, что впервые предпринят всесторонний анализ функционирования "почему"-реплик в русской диалогической речи. Полученные результаты показали, что "почему"-реплики, рассматривающиеся как реакции на модус собеседника, имеют тенденцию переходить в конвенционализованный косвенный речевой акт-возражение на утверждение собеседника или отрицательный ответ на вопрос.

Адрес статьи: www.gramota.net/materials/2/2020/5/23.html

\section{Источник}

Филологические науки. Вопросы теории и практики

Тамбов: Грамота, 2020. Том 13. Выпуск 5. С. 126-130. ISSN 1997-2911.

Адрес журнала: www.gramota.net/editions/2.html

Содержание данного номера журнала: www.gramota.net/materials/2/2020/5/

\section{() Издательство "Грамота"}

Информация о возможности публикации статей в журнале размещена на Интернет сайте издательства: www.gramota.net Вопросы, связанные с публикациями научных материалов, редакция просит направлять на адрес: phil@gramota.net 
В статье представлена попьтка описания особенностей реакций-реплик с вопросительным словом «почему», которые широко распространены в русской диалогической речи. Цель исследования - подробно проанализировать на основе материалов НКРЯ особенности структуры, смысла, прагматической функиии и интонации «почему»-реплик как реакиий на модус. Научная новизна заключается в том, что впервые предпринят всесторонний анализ функционирования «почему»-реплик в русской диалогической речи. Полученные результаты показали, что «почему»-реплики, рассматривающиеся как реакиии на модус собеседни$к а$, имеют тенденцию переходить в конвенционализованный косвенный речевой акт-возражение на утверждение собеседника или отрицательный ответ на вопрос.

Ключевые слова и фразы: «почему» как маркер возражения; реакция на модус; интонация; конвенционализованный косвенный речевой акт; коммуникативная стратегия; русская диалогическая речь.

\title{
Ван Лина
}

Пекинский университет иностранных языков, Китайская Народная Республика

linawang0122@sina.com

\section{Особенности реакций-реплик с вопросительным словом «почему»}

\author{
Работа выполнена при финансовой поддержке иентральных университетов \\ (в рамках научно-исследовательского проекта «Общественный ритуальный дискурс \\ и ритуальный дискурс об отнотениях между людьми», проект № 2019ЈХ010). \\ (中央高校基本科研业务费专项资金资助)
}

«Почему»-реплика как вторая реплика в диалогическом единстве состоит из вопросительной частицы «почему» и цитируемого повторяемого элемента из предшествующей реплики, не имеющих прямой логикосемантической связи. Повторяемая часть является частью «сбоя информации» между говорящим и его собеседником, а также той частью, на которую говорящий возражает или которую отрицает. По мнению М. Д. Смирновой, речевые конструкции с такими вопросительными словами, как «какой», «какое», «что», «чего», «почему», «зачем», «при чем», «куда», «Где» и «как», в определенных речевых контекстах или ситуациях могут выразить возражение, направленное на предшествующее высказывание. Поэтому эти десять вопросительных слов могут рассматриваться в качестве специальных «отрицательных» маркеров [6, с. 205]. В данной статье основное внимание уделяется одному из этих маркеров возражения - «почему», анализируются реакции-реплики, состоящие из вопросительного слова «почему» и цитируемого компонента, подвергаемого отрицанию.

В работе заимствованы соответствующие труды российских (Н. Д. Арутюнова, М. Д. Смирнова и Н. Ю. Шведова) и китайских ученых (Сюй Вэнюй и Юань Ни) о причинных вопросах и вопросительных словах в русском языке, которые составляют теоретическую базу настоящего исследования. Практическая значимость нашей работы заключается в том, что результаты исследования могут быть использованы в курсах по прагматике, а также в преподавании русского языка как иностранного. Следует отметить, что, несмотря на частотность употребления в русской диалогической речи причинных вопросов с вопросительным словом «почему», переходящих в косвенные речевые акты, они описаны в научной литературе далеко не полностью. В этом состоит актуальность выполненного анализа.

В работе в основном использовались три типа методов исследования: описательный метод, метод аргументации на основе материалов НКРЯ и метод семантико-прагматического анализа «почему»-реплик.

Для достижения поставленной цели решались следующие задачи: 1) определить лексический состав и двойственное синтаксическое свойство «почему»-реплик; 2) выявить семантические особенности «почему»-реплик при сохранении вопросительных стимулов и при их нейтрализации; 3) проанализировать прагматическую функцию «почему»-реплик и роль интонации.

Н. Д. Арутюнова, основываясь на предложенном швейцарским лингвистом Ш. Балли делении предложения на диктум и модус, рассматривает диктум как сообщение о содержании предложения, а модус как «субъективное отношение говорящего к сообщению» [1, с. 46]. Оба могут стать стимулами для создания диалога и вызвать различную реакцию со стороны слушающего. Арутюнова относит «почему»-реплики к реакциям, направленным на модус. Например:

- Он ушел.

- Почему ушел? (Ю. Нагибин «Моя золотая теща») [3] (все приводимые в статье примеры взяты из Национального корпуса русского языка (www.ruscorpora.ru)).

На первый взгляд, здесь второй говорящий спрашивает о причине (cause), по которой человек ушел, то есть это как будто реакция на диктум (Почему он ушел?). Но на самом деле настоящей целью второго говорящего является выяснение причины-основания (raison): в соответствии с чем первый говорящий сделал такое утверждение, то есть это реакция на модус (Почему ты думаешь, что он ушел?; Почему ты так считаешь?). В более широком смысле такие «почему»-реплики относятся к приведенным Н. Ю. Шведовой «репликамповторам» [7, с. 70], или «вариационным повторам» [11, с. 116], или «структурным выражениям несобственного повтора» $[12$, с. 21$]$. В настоящей статье «почему»-реплики, обычно состоящие из вопросительной 
частицы «почему» (почему это, почему же) и цитируемой повторяемой части, в дальнейшем именуются просто «почему»-реплики.

\section{1. Формальная структура «почему»-реплик}

\section{1. Лексический состав}

«Почему»-реплика как реакция-реплика состоит из дополнительной и базовой частей. Базовая часть это лексические единицы, повторяемые из первой реплики (стимула-реплики). Этот повторяемый элемент, не заменяемый другими лексическими единицами, выступает «в качестве структурной основы» второй реплики (реакции-реплики) [7, с. 69] и играет строительную роль. Дополнительная часть «почему» используется в качестве особого «отрицательного» маркера для выражения разнообразных отрицательных модальных значений; формирует определенный лексико-грамматический класс и тип повтора второй реплики.

Необходимо отметить, что «почему»-реплика как синтаксическая конструкция, которая включает в себя две не имеющие прямой логико-семантической связи части, широко распространена в русской диалогической речи. По мнению Арутюновой, такие употребления возможны потому, что «причинный вопрос к модусу опирается на явление цитации» [1, с. 55]. Вопросительная частица «почему», скорее всего, относится не к диктуму данного высказывания, а к цитируемой части, взятой из предшествующей реплики. Эти цитируемые слова являются переработанными «воспроизведенными словами» и рассматриваются как стратегия общения, при которой говорящий использует речь собеседника для достижения собственных коммуникативных целей. Отметим, что данная реакция-реплика цитирует в основном отдельное слово или словосочетание из предшествующей реплики, именно то, на что возражает говорящий. К тому же в письменном тексте повторяемый компонент часто берется в кавычки. Например:

- Какие мы товарищи? Он мыкается, а нам - хоть бы что!

- Почему «хоть бы что»? - страдальчески морщился Король (Ф. Вигдорова «Дорога в жизнь») [3].

Таким образом, эта «упрощенная» форма является как раз самой важной структурной характеристикой для «почему»-реплик как реакции на модус и «не имеет ничего общего с явлением эллипсиса» [1, с. 56], конечно же, здесь не упущено ни одного слова, «ничего в ней не восполняет» [7, с. 69].

\section{2. Синтаксическая структура}

«Почему»-реплики как реакции на модус реализуют двойственное синтаксическое свойство.

С одной стороны, в результате семантического повторения, коррелятивного указания и других средств связанности лексический состав и синтаксическое строение реакции-реплики по существу обязательно зависят от стимула-реплики. Без стимула-реплики (первой реплики) не существует реакции-реплики (второй реплики). Такая взаимосвязанность высказываний образует коммуникационную единицу диалога, которая называется «диалогическим единством» [Там же].

А с другой стороны, под влиянием субъективной воли ответчика, «почему»-реплика как реплика, построенная по правилам разговорной речи, имеет свой собственный синтаксический статус и структурные характеристики, проявляет определенную независимость и незаменимость.

1.2.1. Субъективность структуры повторяемого фрагмента

Важно отметить, что повторяемый фрагмент как структурная основа «почему»-реплик может представлять собой те же, что и в первой реплике, лексические элементы, перенесенные во вторую часть без изменений, либо возможны некоторые изменения в форме слов. Все это определяется различными экспрессивными оценивающими реакциями говорящего на то, что сказано. Например:

\section{- Прости его.}

- Почему ж простить? (С. Довлатов «Холодильник») [3].

Здесь адресат заменил повелительное наклонение глагола на форму инфинитива. Такое изменение отражает изменение субъективной модальности говорящего, то есть ответчик, может быть, обращает внимания не на конкретное действие, совершенное конкретным лицом, а только на само действие.

\subsection{2. Случайная выборка стимула}

В структуре предложения принято выделять тему и рему. Тема обычно находится в начале предложения, является отправной точкой в передаче сообщения, а рема, стоящая после темы, передает новую информацию, является центром сообщения [8, p. 34]. В русской диалогической речи рема обычно берет на себя коммуникативную задачу и выступает в качестве компонента речи, стимулирующего ответную реакцию со стороны адресата. Мы знаем, что для выражения своих различных субъективных отношений и мнений говорящий может цитировать любой отдельный элемент предыдущей реплики и использовать «почему»-реплику как реакцию на модус. Это значит, что любой элемент предшествующего высказывания может выступать в качестве стимула, а не только его рема. Таким образом, стимулирующий ответную реакцию элемент может совпадать с ремой высказывания, а может с ней не совпадать. В случае, когда адресат нарушает установленную первой репликой программу общения, реагирует не на ее рему, которая выделена в качестве стимула, а актуализирует несогласованную тему, тогда течение разговора вынуждено отклониться от заданного направления, и ожидаемые коммуникативные эффекты не могут быть достигнуты. Давайте рассмотрим пример:

- Ты говоришь: «Осенило?»

- Почему тебя? Почему сейчас? Обычный воскресный день (А. Волков «Миры Стивена Хоукинга») [3].

В данном диалоге вопросительный фокус адресанта составляет лексема «осенило». Адресант хотел, чтобы данная лексема стала строительной основой второй реплики. Иначе говоря, при нормальном случае адресат должен реагировать на рему «осенило». Тем не менее адресат нарушил такие ожидания: подвергнул отрицанию личное местоимение «ты» и настоящее время, отражаемое предикатным глаголом, далее объяснил неуместность и неадекватность их использования, также обосновал несогласие с собеседником. Слушающий 
не уловил коммуникативных намерений говорящего, поэтому стимул-реплика не выполнила свою миссию общения, в результате чего произошла неуспешная коммуникация (видимо, адресанту придется реализовать речевое действие еще раз).

Итак, как сказано выше, слушающий отклонился от заданной говорящим программы общения, что привело к неудаче коммуникации. Такие случаи являются типичными примерами независимости и субъективности реакции-реплики.

\section{2. Семантические особенности «почему»-реплик}

В «Грамматике-80» с целью описания функционально-семантических типов вопросительных предложений их функции разделены на первичные и вторичные [5, с. 394]. В случае, когда вопросительные предложения выполняют первичные функции, говорящий задает вопросы с намерением получить интересующую его неизвестную информацию. А при условии, что говорящий не ожидает ответа от собеседника, цель использования этих вопросительных предложений заключается только в передаче различных модальных суждений говорящего по поводу ситуации, таких как побуждение, отрицание, оценка, при этом вторичные функции вопросительных предложений обладают абсолютным преимуществом.

Что касается «почему»-реплик как реакций на модус с вопросительной формой, то их семантические характеристики могут быть изучены в двух ситуациях: 1) «почему»-реплика явно направлена к модусу собеседника; 2) «почему»-реплика не требует от собеседника ответа.

\section{1. Сохранение вопросительного стимула}

В случае, когда форма предложения соответствует его функции, то есть предложение с вопросительной формой выполняет свои основные первичные функции, тогда данное предложение оставляет за собой вопросительный стимул. Это значит, что говорящий сомневается, задает вопрос и обращается к собеседнику за ответом, в то же время считая, что собеседник знает ответ. Вот такой пример:

- А почему вы все без галстуков? - спросила вдруг Таня. - Или вы неорганизованные?

Стало очень тихо. Потом Жуков спросил настороженно:

- Почему неорганизованные? Чем мы плохо организованные?

- Ну, то есть, не пионеры. Не пионеры - это и есть неорганизованные (Ф. Вигдорова «Дорога в жизнь») [3].

Можно утверждать, что в данном примере реакция-реплика «Почему неорганизованные?» не только реагирует (отвечает) на заданный Таней вопрос, но и имеет вопросительную функцию, то есть Жуков ожидает от Тани дальнейших объяснений и причины-основания, почему Таня сделала такое утверждение (считала их неорганизованными). Таким образом, говорящий объединил в одной реакции-реплике две функции: непосредственную реакцию на модус стимула-реплики и одновременно обращение к модусу собеседника.

\section{2. Нейтрализация вопросительного стимула}

В противоположном случае, когда форма предложения не соответствует своей функции, предложение представляет только вопросительную форму и не включает в себя (или включает мало) спрошенное содержание. Это значит, что говорящий не стремится к получению от собеседника неизвестной информации, его основная цель состоит в выражении своего субъективного отношения при помощи данного вопросительного выражения. Если это так, то вопросительный стимул данного предложения будет значительно ослаблен и даже утрачен. Проанализируем следующие две ситуации.

2.2.1. «Почему»-реплика как реакция на модус служит интродукцией для отрицательного ответа. В этом случае диалогический стимул данной реплики нейтрализуется, говорящий как будто задает сам себе вопрос и потом сам отвечает. Например:

- Автомобиль-то небось не дадут!

- Почему не дадуm? Дадуm! (И. Антонова «Тринадцатый пират») [Там же].

В этом примере реплика «Почему не дадут?» предваряет будущий отрицательный ответ. Используя данную синтаксическую структуру, говорящий не ждет от собеседника ответа, а выражает свою эмоциональную реакцию на полученное сообщение. Поэтому «почему»-реплики для реакций на модус нередко рассматриваются как собственно диалогическая тактика.

2.2.2. Лишаясь вопросительного стимула, сами «почему»-реплики нередко эквивалентны отрицательной реакции, за которой обычно следует более эксплицитное объяснение и пояснение. Например:

- Ну давайте мириться. Давайте выпьем коньяку.

- Почему мириться? Я с вами не ссорился (А. Чехов «Три сестры») [Там же].

Можно заметить, что в этой коммуникационной структуре ответная роль причинного вопроса «Почему мириться?» уже совершенно явна, то есть Почему мириться? $\approx$ Не нужно мириться. В таком контексте вопросительный стимул данной «почему»-реплики нейтрализован в максимальной степени, а субъективная модальность говорящего, соответственно, проявляется в наибольшей степени.

Необходимо отметить, что в обоих вышеуказанных случаях вопросительная форма «почему»-реплики и ее смысл отходят друг от друга. Несмотря на некоторые вопросительные оттенки, доминирующую роль играет вторичная функция, которая предназначена для передачи различных эмоциональных реакций говорящего. Мы знаем, что говорящий первой реплики хочет получить фактическую информацию от слушающего. Это неоспоримый факт. Поэтому для таких предметных диалогов «почему»-реплики как будто избыточны в информативном отношении и нарушают принцип сотрудничества коммуникации. Ведь следующая за ними «логическая» реакция (то есть собственно информативное содержание) вполне могла бы передать сообщение и осуществить коммуникацию. Ну зачем вообще нужно обилие этих своеобразных «прокладок»? Нужно, потому что они составляют эмоциональную «прокладку» между вопросом и собственным ответом, 
внося богатую модальную насыщенность в диалог информативного, предметного содержания. Более того, они могут выразить различные субъективные эмоциональные реакции собеседника и избавить живой непринужденный разговор от искусственности. К тому же в связи с отсутствием предварительного обдумывания диалогической речи и волновой природой формирования мысли «почему»-реплики могут обеспечить тесную связь между говорящим и слушающим, естественность и эффективность их общения, а также помочь говорящему выиграть время для того, чтобы обдумать слова собеседника и дать разумные ответы. Эти своеобразные «прокладки» нередко называют «рессорные реплики» [1, с. 54] или «дежурные реплики» [2, с. 316].

В вышеупомянутых случаях происходит разделение эмоциональной и рациональной реакции. Такое разделение как раз составляет чрезвычайно характерную черту русской диалогической речи, то есть «реальный русский диалог редко строится путем чередования прямых, лобовых вопросов и ответов» [7, с. 69].

3. Прагматический анализ «почему»-реплик

Как видно из вышесказанного, существует асимметрия в языковой системе. «Почему»-реплики могут выполнять как первичную функцию, так и вторичную. В том случае, когда функция не соответствует их вопросительной форме, в основном действует вторичная функция, тогда вопросительный стимул данного высказывания будет значительно ослаблен или вообще нейтрализован. В этот момент говорящий стремится к осуществлению косвенных речевых актов при помощи данной вопросительной структуры и хочет выражать свои различные субъективные отношения и коммуникативные намерения.

\section{1. «Почему»-реплики как косвенный речевой акт возражения}

Опираясь на теорию речевых актов Дж. Остина, Серль сформулировал теорию косвенных речевых актов. По мнению Серля, косвенный речевой акт имеет место в том случае, «когда один иллокутивный акт осуществляется путем осуществления другого» [9, р. 31]. Косвенный речевой акт включает в себя два иллокутивных акта, Серль называет их «небуквальный первичный иллокутивный акт» и «буквальный вторичный иллокутивный акт». Что касается «почему»-реплики, то говорящий обычно косвенно выражает свое несогласие с суждениями собеседника или «исправляет неправильные или неуместные слова» [10, с. 53] посредством реализации речевого акта вопроса. Например:

- Вы только посмотрите: мужчина...

- $\quad$ А почему мужчина? Это слово женского рода (В. Молчанов «Дорогие страницы памяти») [3].

В этом примере реплика «А почему мужчина?», по-видимому, реализует речевой акт вопроса, то есть вопрос - это второй иллокутивный акт. А в данном контексте ее первичный иллокутивный акт, выражающий настоящее намерение высказывания, естественно воспринимается как возражение против использования слова «мужчина». Важно подчеркнуть, что здесь перформатив не проявлен эксплицитно, но иллокутивная функция косвенно обнаруживается.

\section{2. Вопросительная частица «почему» как особый маркер возражения}

М. Д. Смирнова замечает, что возражение может выражаться по-разному. Но можно утверждать, что «конструкция с вопросительным словом - одна из наиболее употребительных в разговорной речи форм выражения возражения» [6, с. 195]. В речевой структуре «почему»-реплики повторяемая часть является частью «сбоя информации» между говорящим и его собеседником, а также той частью, на которую говорящий возражает или которую отрицает. Таким образом, «почему»-реплики как реакции на модус имеют тенденцию становиться клишированной формулой. Такие реплики с вопросительным словом «почему» могут «переходить в конвенционализованный косвенный речевой акт, выражающий возражение на утверждение собеседника или отрицательный ответ на вопрос» [4, с. 310]. В связи с этим Падучева предложила выражение отношения:

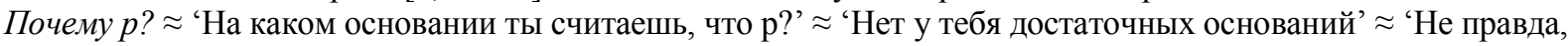
что р’ (здесь р означает повторяемый фрагмент).

Конечно же, далеко не все вопросительные слова могут употребляться в конструкциях со значением возражения. Мы уже обнаружили, что в определенном контексте всего десять вопросительных слов могут рассматриваться в качестве специальных «отрицательных» маркеров. Кроме того, выбор данной стратегии для выражения возражения связан со многими факторами: в каких отношениях находятся говорящий и его собеседник, какие эмоции хочет выразить, насколько он уверен в своей правоте и т.д.

\section{4. Интонационные черты «почему»-реплик}

Как видим, «почему»-реплики как причинные вопросы, реагирующие на модус предшествующей реплики, имеют структурные, семантические и прагматические признаки, отличающиеся от соответствующих признаков причинных вопросов, непосредственно относящихся к диктуму. Но иногда между ними возникает «коммуникативная близость» [1, с. 57], тогда их различение представляется затруднительным. Особенно когда субъектом диктума является само говорящее лицо и содержание диктума имеет ярко субъективный модальный характер, различия в их структуре и смысле будут нивелированы. Таким образом, данные два типа причинных вопросов могут попадать в одинаковую диалогическую рамку, то есть имеют одинаковую стимулреплику и вызывают одинаковую ответную реплику. Например:

- Все это очень серьезно и... горестно.

- Почему горестно?

- Сами узнаете в свой час. Старый Лев Толстой плакал по каждому поводу, для окружаюших без всякого повода (А. Зиганшина «Полкило золота — и ни одной мини-юбки!») [3].

В данной диалогической структуре реплика «Почему горестно?» может быть объяснена как: 1) Почему $8 b$ считаете, что все это очень серьезно и горестно?; 2) Почему все это очень серьезно и горестно?. Нельзя не видеть, что каким бы ни было объяснение, оно не приведет к изменению структуры и значения диалога, также не повлияет на реализацию коммуникативных целей говорящего. Такая коммуникативная близость 
создает условия для снятия смысловых и формальных различий между двумя типами причинных вопросов. Для их различия основную роль выполняет интонация.

Нам кажется уместным еще раз подчеркнуть значимость интонации. Интонация играет очень важную роль для понимания содержания высказывания. Арутюнова изображала интонацию как жест, считая, что «интонационный жест» самым непосредственным образом относит высказывание к действительности в диалоге, то есть относит словесный знак к денотату [1, с. 50]. Действительно, интонация не только регулирует отношения между людьми, но и передает разную модальную информацию. Что касается «почему»-реплик как реакций на модус, то в произношении имеется легкая пауза, отделяющая вопросительное слово «почему» от цитируемой повторяемой части, и повторяемая часть обычно произносится напряженным тоном. Следует отметить, что данный перебой в интонации как раз удовлетворяет потребность говорящего в выражении субъективных отношений к цитируемой части, естественно отличает «почему»-реплику с ориентацией на модус от омонимичного ей причинного вопроса, относящегося к диктуму. Важно подчеркнуть, что при редукции «почему»реплик к вопросительному слову: Почему? Почему же? Ну почему? и др., кроме специфического интонационного рисунка, для их различия еще нужно учитывать участие жеста, мимики и пр. говорящего.

Итак, изучение особенностей «почему»-реплик с ориентацией на модус позволяет прийти к следующим выводам:

1. Данный тип реакций-реплик в своем лексическом составе и синтаксическом строении по существу обязательно зависит от стимула-реплики. В то же время «почему»-реплики, построенные по правилам разговорной речи, имеют свой собственный синтаксический статус и структурные характеристики, проявляют определенную независимость и незаменимость.

2. При сохранении вопросительных стимулов «почему»-реплики выполняют свои основные первичные функции, говорящий сомневается, задает вопрос и обращается к собеседнику за ответом; а при их нейтрализации для вопросительной формы «почему»-реплики доминирующую роль играет вторичная функция, которая предназначена для передачи различных эмоциональных реакций говорящего.

3. «Почему»-реплики как реакции на модус имеют тенденцию становиться клишированными формулами. Такие реплики с «почему» могут переходить в конвенционализованный косвенный речевой акт, выражающий возражение на утверждение собеседника или отрицательный ответ на вопрос. При возникновении коммуникативной близости «почему»-реплики и причинного вопроса интонация, жест, мимика и другие невербальные средства играют основную смыслоразличительную роль.

Список источников

1. Арутюнова Н. Д. Некоторые типы диалогических реакций и «почему»-реплики в русском языке // Научные доклады высшей школы. Филологические науки. 1970. № 3. С. 44-58.

2. Булыгина Т. В. Диалогические функции некоторых типов вопросительных предложений // Известия Академии наук СССР. Серия литературы и языка. 1982. Т. 41. № 4. С. 314-326.

3. Национальный корпус русского языка [Электронный ресурc]. URL: http://www.ruscorpora.ru (дата обращения: 21.04.2020).

4. Падучева Е. В. Прагматические аспекты связности диалога // Известия Академии наук СССР. Серия литературы и языка. 1982. Т. 41. № 4. С. 305-313.

5. Русская грамматика: в 2-х т. М.: Институт русского языка им. В. В. Виноградова РАН, 2005. Т. 2.712 с.

6. Смирнова М. Д. Функции вопросительных слов в возражении // Дискурсивные слова русского языка: контекстное варьирование и семантическое единство: сборник научных трудов. М.: Азбуковник, 2003. 207 с.

7. Шведова Н. Ю. К изучению русской диалогической речи // Вопросы языкознания. 1956. № 2. С. 67-82.

8. Halliday M. A. K. An Introduction to Function Grammar. L.: Edward Arnold, 1994. 700 p.

9. Searle J. R. Expression and meaning: Studies in the theory of speech acts. Cambridge: Cambridge University Press, 1979. 201 p.

10. 武瑗华, 从语用逻辑看反驳[J], 解放军外国语学院学报, 2010 (4), 页 49-53 (Ву Айхуа. Анализ возражения с точки зрения прагматической логики // Вестник Института иностранных языков НОАК. 2010. № 4. С. 49-53).

11. 徐翁宇, 俄语对话分析 $[\mathrm{M}]$, 北京 : 外语教学与研究出版社, 2008, 295页 (Сюй Вэнюй. Анализ русской диалогической речи. Пекин, 2008. 295 с.).

12. 袁妮, 现代俄语答话语句[J], 中国俄语教学, 1990 (04), 页 18-22 (Юань Ни. Ответные реплики в современной русской речи // Русский язык в Китае. 1990. № 4. С. 18-22).

\title{
Specificity of Responsive Replicas with the Interrogative Word "Why"
}

\author{
Wang Lina \\ Beijing Foreign Studies University, the People's Republic of China \\ linawang0122@sina.com
}

The article describes specificity of responsive replicas with the interrogative word "why" that are widely used in the Russian dialogic speech. The research objective includes analysing the structure, meaning, pragmatic function and intonation of "why"replicas as responses to the modus. The study is based on the Russian National Corpus data. Scientific originality of the research lies in the fact that the author for the first time provides a comprehensive analysis of "why"-replicas functioning in the Russian dialogic speech. The findings indicate that "why"-replicas considered as responses to the interlocutor's modus tend to transform into a conventionalized indirect speech act - objection to the interlocutor's claim - or a negative reply to a question.

Key words and phrases: "why" as marker of objection; response to modus; intonation; conventionalized indirect speech act; communicative strategy; Russian dialogic speech. 